\title{
Simulation of Biodiesel and Petrodiesel Pollutant Kinetics
}

\author{
$\underline{\text { G. Cai }}{ }^{1}$ and J. Abraham ${ }^{1,2}$ \\ ${ }^{1}$ School of Mechanical Engineering, University of Adelaide, North Terrace, SA 5005, Australia \\ ${ }^{2}$ School of Mechanical Engineering, Purdue University, West Lafayette, Indiana, USA \\ Email: gary.cai@adelaide.edu.au
}

\begin{abstract}
Biodiesel is considered as an attractive alternative to petrodiesel for transportation applications. Substituting petrodiesel with domestically produced biodiesel increases energy independence, reduces the carbon footprint, and offers a viable path toward biomass utilisation. It has been found that biodiesel-fuelled engines emit up to $70 \%$ lower particulate matter (PM) compared to petrodiesel-fuelled engines, although they emit up to $20 \%$ more nitric oxides $\left(\mathrm{NO}_{\mathrm{x}}\right)$. In this study, simulations are employed to improve the fundamental understanding of biodiesel and petrodiesel combustion under pressure and temperature conditions in engines. n-Heptane is used as the surrogate for petrodiesel fuel and a ternary mixture of methyl decanoate, methyl-9decenoate, and n-heptane as the surrogate for biodiesel fuel. The choice of chemical kinetic mechanism is a compromise between computational time and accuracy. Four mechanisms are evaluated and a 160-species skeletal chemical kinetic mechanism is employed to model the oxidation of $n$-heptane. The computational time is shown to increase dramatically as the complexity of the mechanism increases. Soot kinetics is represented using a chemical mechanism that models the growth of soot precursors starting from a single aromatic ring and growing by hydrogen abstraction and carbon (acetylene) addition. $\mathrm{NO}_{\mathrm{x}}$ kinetics is represented using the thermal, prompt, and intermediate mechanisms. In the case of the ternary biodiesel surrogate, a 211-species reduced mechanism is employed to model the chemical kinetics. This mechanism was derived as part of this work by combining reactions from the 160 -species n-heptane mechanism with reactions from a skeletal 115-species mechanism proposed in the literature. The influence of turbulence is modeled through an imposed strain rate in the simulations.
\end{abstract}

The computations are carried out using a strained laminar flamelet code (SLFC). In addition to exploring the effect of strain rate (turbulence) on the ignition, extinction, and pollutant formation characteristics, the fundamental chemical pathways that lead to $\mathrm{PM}$ and $\mathrm{NO}_{\mathrm{x}}$ formation are studied by considering the evolution of precursor species. In general, ignition and extinction of flames in biodiesel combustion are more sensitive to turbulence than in petrodiesel flames. Soot volume fraction is lower in biodiesel combustion compared to petrodiesel combustion. This is consistent with measurements reported in engines. NO concentration is, however, lower for biodiesel combustion when considering kinetics alone, suggesting that the volume phasing and operating parameters of engines influence observed NO results in engine emissions where NO is observed to be higher in biodiesel-fuelled engines. It is shown that while increasing strain reduces soot formation for both fuels, the reduction is significantly greater for biodiesel suggesting that increased mixing has a greater effect on PM emissions in biodiesel-fuelled engines.

Keywords: $\quad$ Biodiesel, Kinetics, Soot, Combustion, Engines 


\section{INTRODUCTION}

Energy consumption and climate change are two global challenges that need to be addressed. In developed countries, the transportation sector is responsible for about $25 \%$ of energy consumption and about $30 \%$ of carbon emissions (EIA, 2013). More efficient and clean-burning engines will positively impact these statistics. Direct-injection compression-ignition (DICI) engines, often referred to as diesel engines because they primarily run on petrodiesel fuel, are more efficient than petrol engines, by as much as $30 \%$, because of their higher compression ratio. They are widely employed in Australia and throughout the world for heavyduty highway transportation and off-highway applications, e.g. mining, farming. They are also employed for rail and marine transport. In many parts of the world, diesel engines are also extensively employed for lightduty applications. Overall, diesel fuel usage for road vehicles was at about $40 \%$ of the total fuel consumption in Australia (ABS, 2012). However, diesel engines in their current state are a significant contributor of particulate matter $(\mathrm{PM})$ and nitrogen oxides $\left(\mathrm{NO}_{\mathrm{x}}\right)$ emissions. There is a clear need to develop engines which generate lower $\mathrm{PM}$ and $\mathrm{NO}_{\mathrm{x}}$ emissions without compromising the high-efficiency of conventional diesel engines. One approach is to develop DICI engines which run on biodiesel.

Biodiesel is attractive because substitution of petrodiesel with biodiesel results in a net reduction in carbon emissions on a life-cycle basis (Searchinger et al., 2008) when changes in land-use is not accounted for. Substitution of petrodiesel with biodiesel reduces dependence on imported petroleum and improves energy security. The well known differences between biodiesel and petrodiesel-fuelled have been repeatedly emphasised (Lapuerta et al., 2008). These include reduced PM emissions (by as much as 70\%), increased $\mathrm{NO}_{\mathrm{x}}$ emissions (as much as 20\%), reduced carbon monoxide (CO) and unburned hydrocarbon (UHC) emissions, and increased aldehyde emissions when petrodiesel is substituted by biodiesel. Many of the studies are carried out in engines and it is difficult to extract fundamental reasons for the differences from such studies because multiple variables are changing simultaneously. There is a need for fundamental studies.

Flames in DICI engines have the structure of a diffusion flame. These flames are strained by the influence of the background turbulent flow field (Peters, 2000). In this work, the structure of petrodiesel and biodiesel strained diffusion flames are studied using skeletal kinetic mechanisms to represent fuel oxidation. Soot and $\mathrm{NO}_{\mathrm{x}}$ are modelled using kinetic mechanisms. The computational tools and kinetic mechanisms will be discussed in the next section. The results from the study will be presented and discussed in the following section. The paper will then end with a summary and conclusions.

\section{COMPUTATIONAL APPROACH}

Petrodiesel is a fuel consisting of over 100 hydrocarbons (Pitz and Mueller, 2011). The direct chemical kinetic modelling of all the components is computationally intensive even if kinetic mechanisms were available for all of them. As a result, a surrogate fuel is used to represent the average properties (kinetic, physical) of the fuel. For this study, n-heptane $\left(\mathrm{C}_{7} \mathrm{H}_{16}\right)$ is used as the surrogate for petrodiesel. It has been shown to represent the chemical kinetics of petrodiesel reasonably well (Abraham \& Pickett, 2010; Pitz and Mueller, 2011; Bajaj et al., 2012). For n-heptane, several mechanisms are available with varying levels of accuracy and complexity. Mechanisms considered as part of this work include ones with the following number of reacting species: 37 species (Maroteaux and Noel, 2006), 44 species (Liu et al., 2004), 160 species (Seiser et al., 2000), and 654 species (Mehl et al., 2012). The choice of the appropriate mechanism is a compromise between computational time and accuracy. Table 1 shows the computed ignition delay in milliseconds. The ignition delay time is defined here as the time at which peak temperature first reaches above 1,500 K. Table 1 also shows the computational time (wall clock-time) for computing flame development for $0.5 \mathrm{~ms}$ after the ignition delay time. This was done by using the solution obtained for the ignition delay study and using it as initial value. The computations are run on 12 cores of a 16-core AMD Opteron 6276 processor through MPI (message passing interface). It can be seen that the computational time scales with approximately the square of the number of species. Based on the initial computations, it was decided that that the 160 -species mechanism provided the best balance between computational time and accuracy. In addition, it was sufficiently detailed for coupling with soot kinetics.

Table 1. Ignition delay and calculation times of different $n$-heptane mechanisms.

\begin{tabular}{ccc}
\hline Mechanism & Ignition Delay $(\mathrm{ms})$ & Computational Time(s) \\
\hline 37 Species & 0.32 & 75 \\
44 Species & 0.56 & 95 \\
160 Species & 0.37 & 2,712 \\
561 Species & 0.44 & 33,204 \\
\hline
\end{tabular}


The composition of biodiesel is simpler than of petrodiesel (Herbinet et al., 2008). Nevertheless, the detailed oxidation kinetics of all the biodiesel components is not known. For this research, a ternary biodiesel surrogate (TBS) is used (Herbinet et al., 2010). The TBS consists of three components: $25 \%$ methyl decanoate (MD), 25\% methyl-9-decenoate (MD9D) and 50\% n-heptane. The TBS mechanism employed is a 211-species mechanism developed as part of this work which combines a 115-species skeletal mechanism (Luo et al., 2012) with additional reactions from the 160-species n-heptane mechasnims that influence soot kinetics. Soot is modeled using a kinetic mechanism which is based on the understanding that soot precursors grow through hydrogen-abstraction $\mathrm{C}_{2} \mathrm{H}_{2}$-addition (HACA) (Wang and Frenklach, 1994; Appel et al., 2000). The NO mechanism from the GRI-Mech 3.0 is employed (Smith, 1999).

A strained laminar flamelet code (SLFC) (Gopalakrishnan, 2003; Gopalakrishnan and Abraham, 2004) is employed to compute strained diffusion flames under engine conditions. SLFC is a one-dimensional code which models a laminar diffusion flamelet by transforming the physical space into mixture fraction $(Z)$ space which is then discretized into 51 grid points. The 51 grid points vary in density, with the highest density of the grid points close to the stoichiometric $\mathrm{Z}$ value $\left(\mathrm{Z}_{\mathrm{st}}\right)$. The level of turbulence is varied by changing the scalar dissipation rate $(\chi) \cdot \chi$ is a representation of strain. The scalar dissipation rate is defined as the product of the molecular diffusivity and the square of the physical gradients of mixture fraction. In this sense, it is directly related to the thickness of the flame. For the laminar diffusion flame, $\chi$ is represented by an error function profile (Peters, 2000). SLFC then solves the one-dimensional transient equations for species and energy (Peters, 2000). SLFC is fully parallelized using MPI and written in Fortran90. Reaction pathway analysis is carried out by employing CHEMKIN (Reaction Design, 2010). CHEMKIN is a software package primarily developed to study chemical kinetics under a variety of conditions. The heart of the software is a highly-efficient coupled solver for ordinary differential equations.

\section{RESULTS AND DISCUSSION}

In a DICI engine, liquid fuel is directly injected into the cylinder when the piston is approaching its minimum volume position (top-dead-centre) resulting in a fuel spray as shown in Fig. 1 (Dec, 1997; Westbrook, 2000). The liquid drops vaporise and beyond a certain axial distance only vapour fuel exists. Ignition occurs in the vapour fuel and a flame surrounds the vapour jet. The flame has the structure of a turbulent diffusion flame. The flame is located along the stoichiometric boundary and it is relatively thin and referred to as a flamelet (Peters, 2000). The flame is usually lifted off from the injector (Bajaj et al., 2012). It has been suggested that near the lift-off height of the flame, a rich premixed zone of fuel and air exists. Downstream of this region, polycyclic aromatic hydrocarbons (PAHs), which are soot precursors, form. The PAHs develop into soot further downstream in the jet. The maximum concentration of soot is found in the head-vortex region of the jet (Dec, 1997).

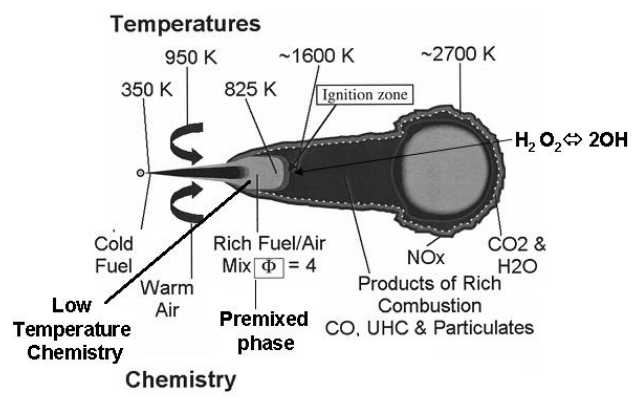

Figure 1. Conceptual picture of a combustion diesel-jet (Dec, 1997; Westbrook, 2000).

As the fuel is injected at a high velocity $(600 \mathrm{~m} / \mathrm{s})$ into the cylinder, the turbulence levels, and hence the strain rate, are highest close to the injector. At this level of strain, heat and chemical species are carried away faster than reactions can self-sustain. As the fuel spray penetrates farther into the cylinder, the local strain rate decreases until it is low enough for autoignition to take place. The strain rate at which ignition occurs is the ignition strain limit $\left(\chi_{\text {ign }}\right)$. It has been suggested that the lift-off height, which affects pollutant formation by varying the amount of air entrained into the fuel spray, is related to the ignition strain rate. If the flame is already established and strain is increased, turbulence will diffuse the heat and species away from the reaction zone. This causes the peak flame temperature to decrease. A level of strain will be reached where the flame completely extinguishes. This is known as the extinction strain limit $\left(\chi_{\text {ext }}\right)$. The ignition and extinction strain rates can be considered as properties of the fuel. In combustion, ignition and extinction are referred to as the "limit phenomena". 
To study the limit phenomena for the surrogate fuels, SLFC is initialised to simulate conditions in a DICI engine. Recall that the solution is in $Z$-space. The temperature boundary conditions for air $(Z=0.0)$ is 1,000 $\mathrm{K}$ and for fuel $(\mathrm{Z}=1.0)$ is $373 \mathrm{~K}$. These temperatures represent compression temperature in the cylinder and injected liquid fuel temperature, respectively. The pressure is assumed to be $42 \mathrm{~atm}$ in this work. The numerical timestep is $5 \times 10^{-7} \mathrm{~s}$. This time step, however, has to be determined for individual computations to ensure that it is much shorter than the reaction time scale. In this work, $\chi$ will employed rather than strain rates as the equations solved in SLFC are flamelet equations. The ignition $\chi$ will be determined by running the simulation at a relatively high $\chi$ and gradually reducing the $\chi$ until autoignition occurs. The autoignition process is shown in Fig. 2a. The initial temperature profile reflects the initial boundary condition profile. By $0.6 \mathrm{~ms}$, ignition has occurred and the peak flame temperature is reached. By $1.5 \mathrm{~ms}$, a steady temperature profile is achieved. The $\chi_{\text {ext }}$ will be determined by taking a steady flame computed at a relatively low $\chi$, such as $5 \mathrm{~s}^{-1}$, and increasing the $\chi$ until the flame is extinguished. This process is shown in Fig. $2 \mathrm{~b}$ when the imposed $\chi$ on the steady profiles is $1542 \mathrm{~s}^{-1}$. The flame starts off with a steady initial profile, and the peak temperature gradually decreases with time until it is extinguished.
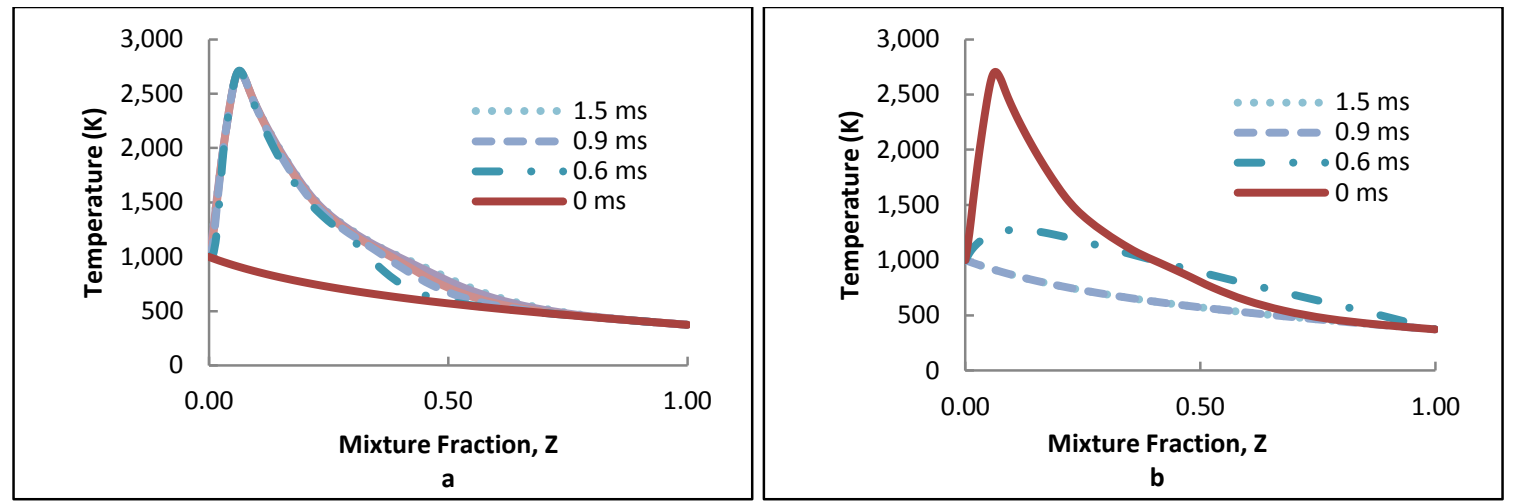

Figure 2. Temperature evolution at the a) $\chi_{\text {ign }}$ of $59 \mathrm{~s}^{-1}$ and b) $\chi_{\text {ext }}$ of $1542 \mathrm{~s}^{-1}$

The $\chi_{\text {ign }}$ and $\chi_{\text {ext }}$ for the two surrogate fuels are shown in Table 2 . For the TBS, both the $\chi_{\text {ign }}$ and $\chi_{\text {ext }}$ are lower than that for $n$-heptane. This implies that the level of turbulence in the cylinder for biodiesel-fuelled engines has to be lower than that in petrodiesel-fuelled engines for autoignition to occur. This also implies that the flame lift-off height is greater for biodiesel. As the lift-off height is increased, more air is entrained into the pre-mix region and this may be a cause for the lower levels of PM and higher levels of $\mathrm{NO}_{\mathrm{x}}$. The lower levels of $\chi_{\text {ext }}$ for TBS suggest that the level of turbulence in the cylinder must be lower in biodiesel-fuelled engines to prevent flame extinction. This has implications on engine design for biodiesel-fuelled engines.

Table 2. Ignition and extinction limits for the two fuel surrogates.

\begin{tabular}{ccc}
\hline Surrogate Fuel & $\chi_{\text {ign }}\left(\mathrm{s}^{-1}\right)$ & $\chi_{\text {ext }}\left(\mathrm{s}^{-1}\right)$ \\
\hline n-heptane & 188 & 4375 \\
TBS & 50 & 2500 \\
\hline
\end{tabular}

The two pollutants of greatest interest in compression-ignition engines are $\mathrm{PM}$ and $\mathrm{NO}_{\mathrm{x}}$. As mentioned in Section 2, soot growth is modelled in SLFC by using the HACA mechanism. In the HACA mechanism, PAH growth into soot begins with a benzene ring (A1). Hydrogen is abstracted and the benzene radical that results reacts with $\mathrm{C}_{2} \mathrm{H}_{2}$ to form phenylacetylene $\left(\mathrm{A}_{1} \mathrm{C}_{2} \mathrm{H}\right)$. Hydrogen is abstracted again from $\mathrm{A}_{1} \mathrm{C}_{2} \mathrm{H}$ and it forms naphthalene (A2). The process is repeated where phenalene (A3), pyrene (A4) and, eventually, soot is formed. There are three mechanisms responsible for the formation of $\mathrm{NO}_{\mathrm{x}}$. The prompt mechanism (Fenimore, 1972) occurs in regions with rich mixture fractions and the $\mathrm{N}_{2} \mathrm{O}$ mechanism (Correa, 1993) occurs in lean mixture fractions. The thermal mechanism (Bowman, 1975) occurs at temperatures above $1,800 \mathrm{~K}$ and is the dominant mechanism in a DICI engines due to the high temperatures in the cylinder. The chemical kinetic mechanisms for both soot growth and $\mathrm{NO}_{\mathrm{x}}$ will be added to the surrogate petrodiesel mechanism and the TBS mechanism. This forms a 253-species n-heptane mechanism and a 304-species TBS mechanism.

The formation of these pollutants is influenced by turbulence characteristics in addition to thermodynamic parameters. Recall that in the computations reported herein, the influence of the turbulence is modelled through the scalar dissipation rate $(\chi)$. It is expected that increasing $\chi$ will decrease the soot formation and increase soot oxidation although the precise trends are likely to depend on the range of values of $\chi$. Another important consideration in the modelling of pollutants is that, unlike the species in the primary fuel mechanism which reach steady concentration values within 1-2 ms after ignition, the concentration of the 
soot precursors and soot itself do not reach steady values for the durations of interest in compression-ignition engines. In addition, ignition delay is dependent on $\chi$. Thus, if the sample time for recording soot production starts from $0 \mathrm{~s}$, it would include the time taken for autoignition. The computations are, as a result, run with a numerical timestep of $5 \times 10^{-7} \mathrm{~s}$ for a total time of $3 \mathrm{~ms}$. The output is logged every $1 \times 10^{-5} \mathrm{~s}$ to accurately capture the autoignition process. Soot production is recorded from the time when the peak temperature has reached $1,500 \mathrm{~K}$, an arbitrary criterion for autoignition. An extra $1.5 \mathrm{~ms}$ is added to this time and the volume fraction of soot, $\mathrm{f}_{\mathrm{v}}$, is recorded. The initial conditions will be the same as for the limit phenomena studies above. Results will be presented for $\chi$ of $5 \mathrm{~s}^{-1}$ and $50 \mathrm{~s}^{-1}$. The results at the two values of $\chi$ highlight the influence of this parameter.

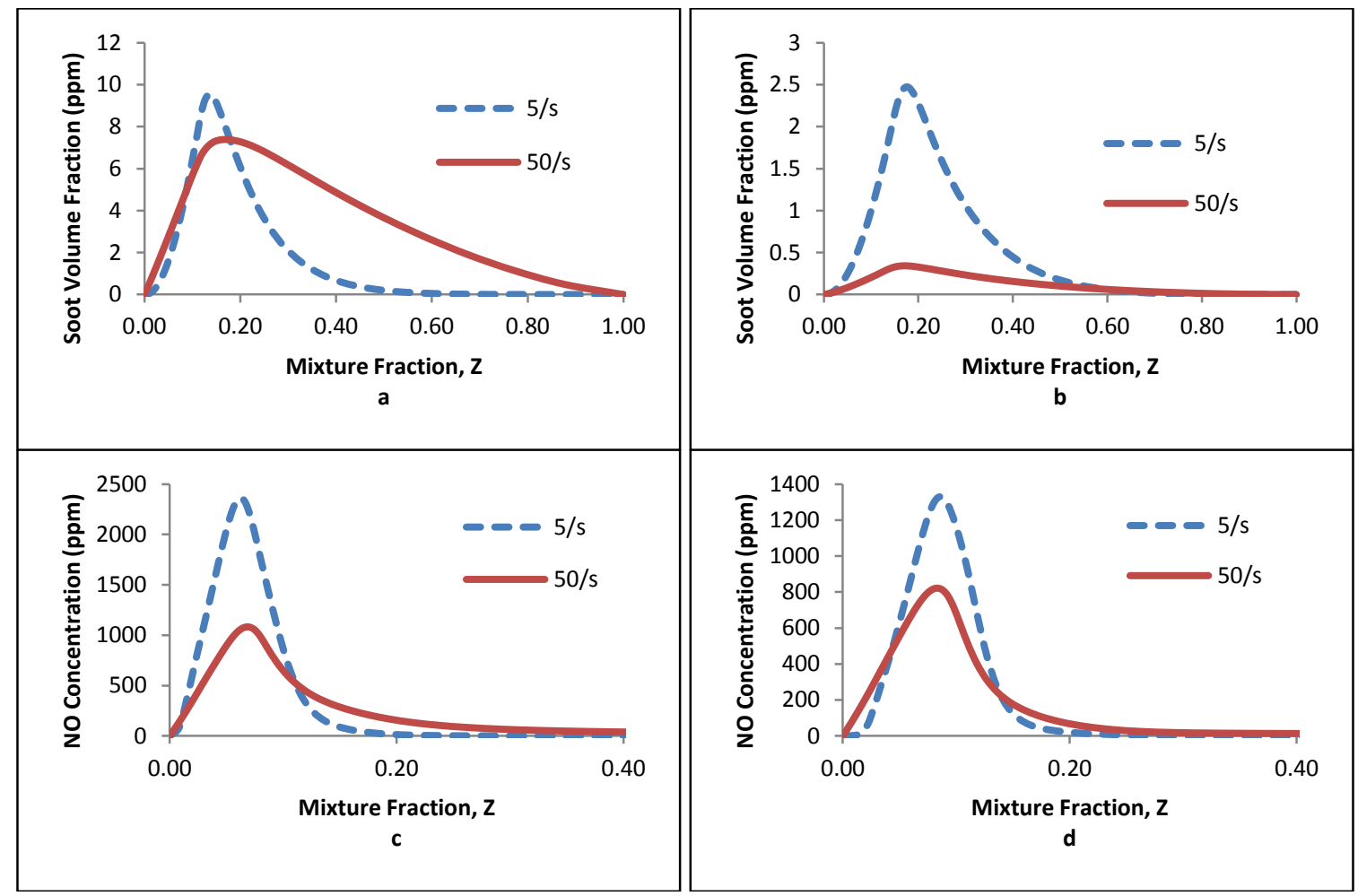

Figure 3. Pollutant concentrations against mixture fraction for a) soot volume fraction in $n$-heptane, b) soot volume fraction in TBS, c) NO concentration in n-heptane, and d) NO concentration in TBS.

Figures $3 \mathrm{a}$ and $3 \mathrm{~b}$ show the soot volume fraction at $1.5 \mathrm{~ms}$ after ignition for $\mathrm{n}$-heptane and TBS, respectively. It can be clearly seen that at $5 \mathrm{~s}^{-1}$ the volume fraction of soot in TBS is about 4 times lower. As $\chi$ is increased to $50 \mathrm{~s}^{-1}$, the volume fraction of soot decreases more for TBS than for $n$-heptane. This suggests that the greater mixing (diffusion in the mixture fraction space) results in reduced formation rates and increased oxidation rates. While it is clear that soot formation in TBS is more sensitive to increase in $\chi$ than in $n$ heptane, the reasons for this have to be investigated. Increasing turbulence has a greater impact on soot formation in biodiesel engines compared to petrodiesel engines. Figure $3 \mathrm{c}$ and $3 \mathrm{~d}$ shows the NO concentration for $n$-heptane and TBS, respectively. As $\chi$ is increased, the NO concentration in both n-heptane and TBS decrease by a similar rate. This suggests that the influence of strain on NO is purely due to thermal reasons. As $\chi$ is increased, the peak flame temperature is decreased and results in a lower concentration of NO formed. From a practical point of view, lower levels of turbulence are needed to reduce soot in biodiesel engines compared to petrodiesel engines. If this conclusion holds, it is significant in that it suggests that engine designers have to invest less effort in generating turbulence in a biodiesel-fuelled engine or, alternatively, the turbulence generated will have a greater impact in the biodiesel-fuelled engine.

The differences in soot volume fractions between n-heptane and TBS are investigated further. Figure 4a shows the differences in soot volume fraction between $n$-heptane and TBS at $5 \mathrm{~s}^{-1}$ and $1.5 \mathrm{~ms}$ after ignition. Recall that soot is formed through PAH precursors. In the HACA mechanism, benzene (A1) and $\mathrm{C}_{2} \mathrm{H}_{2}$ are two important starting species for further growth. The differences in soot volume fraction between n-heptane and TBS would, thus, have originated in differences in $\mathrm{A} 1$ and/or $\mathrm{C}_{2} \mathrm{H}_{2}$. Figure $4 \mathrm{~b}$ shows the $\mathrm{C}_{2} \mathrm{H}_{2}$ mass fraction for both surrogate fuels for the same $\chi$ and time. Though there are noticeable differences in $\mathrm{C}_{2} \mathrm{H}_{2}$, 
these differences do not explain the large differences in soot. Figure 4c show the concentration of the A1 species for the two surrogates. The differences in concentration are, in fact, of the same order of the differences in soot volume fraction. These differences in $\mathrm{A} 1$ and $\mathrm{C} 2 \mathrm{H} 2$ concentrations appear to have a compounding effect on the formation of A4 as Fig. 4d shows. Notice that the differences in A4 concentration are greater than the differences in A1 concentration.

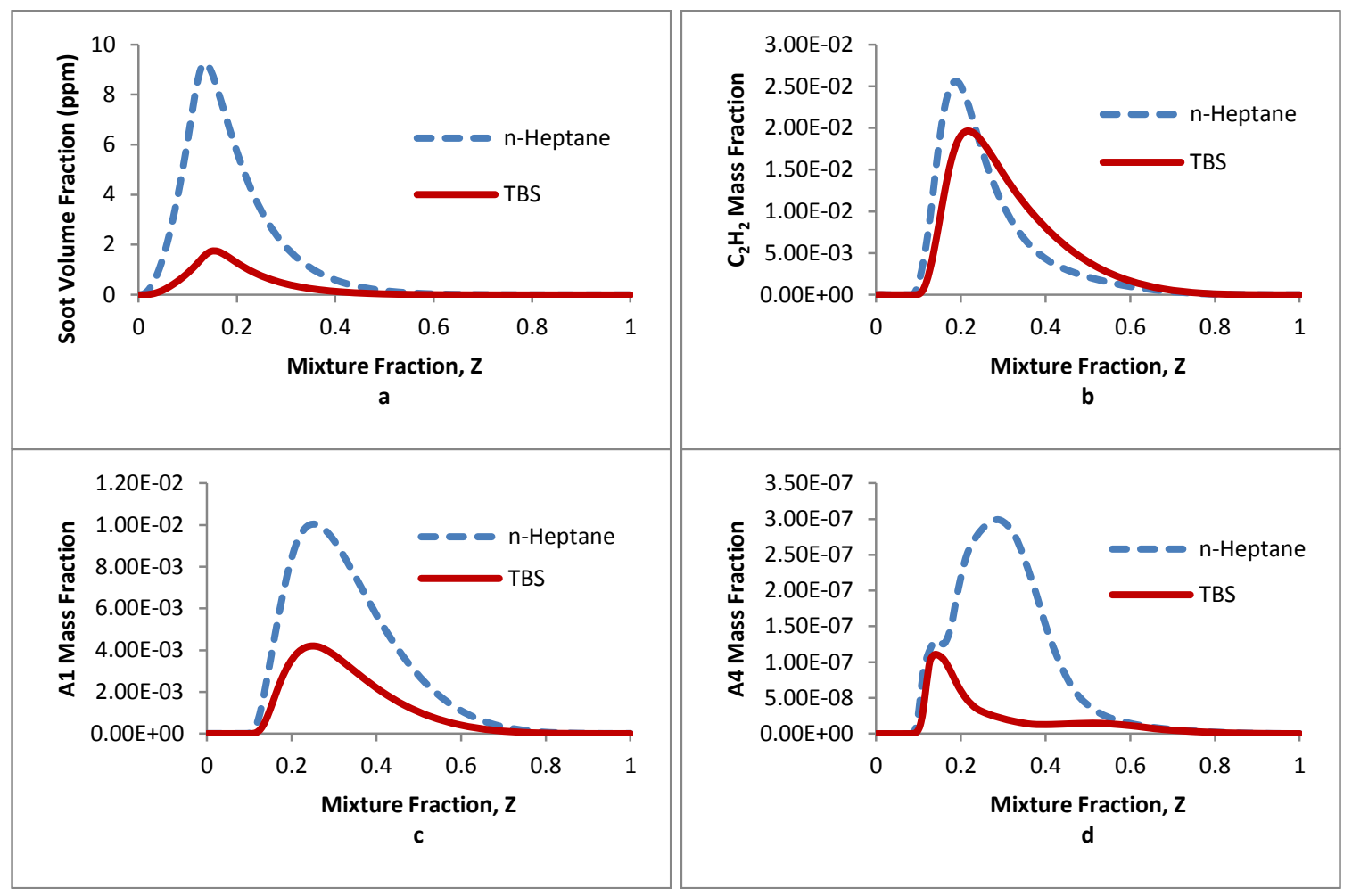

Figure 4. Soot and soot precursor concentrations for n-heptane and TBS; a) soot, b) $\mathrm{C}_{2} \mathrm{H}_{2}$, c) A1, and d) A4.

It then becomes interesting to investigate what causes the difference between the A1 mass fractions for nheptane and TBS. To do this, CHEMKIN will be employed to trace the reaction pathways that forms A1 in the fuel oxidation of n-heptane and TBS.

\section{SUMMARY AND CONCLUSIONS}

In this work simulations employing chemical kinetic mechanisms are carried out in the framework of a strained laminar flamelet code to provide insight into chemical kinetic effects on differences in the performance of petrodiesel and biodiesel-fuelled engines. Chemical kinetic mechanisms for petrodiesel and biodiesel fuels are not available. N-Heptane is employed as the surrogate for petrodiesel and biodiesel fuels are not available. Thus, surrogates are used instead. n-Heptane is employed as the surrogate for petrodiesel and a ternary combination of methyl decanoate, methyl-9-decenoate, and n-heptane as a surrogate for biodiesel. The effects of turbulent strain are represented through the scalar dissipation rate in the equations. The work has shown that fundamental differences in fuel chemistry have a significant effect on combustion characteristics that influence engine emissions and performance. The ignition and extinction strain rates of the biodiesel surrogate fuel are lower than the petrodiesel surrogate. Soot volume fraction is lower in biodiesel combustion. As strain rate is increased, the soot volume fraction decreases at a much larger rate in biodiesel combustion due to the increased oxidation of soot and its precursors compared to petrodiesel combustion. An investigation into the reaction pathway for soot formation revealed that the difference in mass fraction of the initial aromatic species is responsible for the differences in soot volume fraction. The NO mass fraction is predicted to be lower in biodiesel combustion than in petrodiesel combustion suggesting that the increase in NO emissions in engines is probably a result of changes in engine operating parameters, e.g injection and ignition timing. 


\section{ACKNOWLEDGEMENTS}

The authors thank Professor Bassam Dally and Dr. Zhao Tian for their feedback on this work. They also thank the School of Mechanical Engineering at the University of Adelaide and eResearch SA for providing access to computational resources.

\section{REFERENCES}

Abraham, J. and L.M. Pickett (2010). Computed and measured fuel vapor distribution in a diesel spray, Atomization and Sprays, 20, 241-250.

ABS (2012). Motor Vehicle Census, Australia, Australian Bereau of Statistics, 9309.

Appel, J., H. Bockhorn and M. Frenklach (2000). Kinetic modeling of soot formation with detailed chemistry and physics: laminar premixed flames of $\mathrm{C}_{2}$ hydrocarbons, Combustion and Flame, 121, 122-136.

Bajaj, C., M. Ameen and J. Abraham (2012). Evaluation of an unsteady flamelet progress variable model for autoignition and flame lift-off in diesel jets, Combustion Science and Technology, 454-472.

Bowman, C. T. (1975). Kinetics of pollutant formation and destruction in combustion, Progress in Energy and Combustion Science, 1, 33-45.

Correa, S.M. (1993). A review of NOx formation under gas-turbine combustion conditions, Combustion science and technology, 87, 329-362.

Dec, D.J.E. (1997). A conceptual model of DI diesel combustion based on laser-sheet imaging, $S A E$ Technical Paper 970873.

Design, R. (2010). CHEMKIN-PRO, Reaction Design Inc., San Diego.

EIA (2013). International Energy Statistics, U.S. Energy Information Administration. URL: <http://www.eia.gov/cfapps/ipdbproject/IEDIndex3.cfm?tid=44\&pid=44\&aid=2>

Fenimore, C. (1972). Formation of nitric oxide from fuel nitrogen in ethylene flames, Combustion and Flame, 19, 289-296.

Gopalakrishnan, V. (2003). Modeling combusting diesel jets: The free jet regime. PhD Thesis, Purdue University, West Lafayette, IN, USA.

Gopalakrishnan, V. and J. Abraham (2004). Computed NO and soot distribution in turbulent transient jets under diesel conditions, Combustion science and technology, 176, 603-641.

Herbinet, O., W.J. Pitz and C.K. Westbrook (2008). Detailed chemical kinetic oxidation mechanism for a biodiesel surrogate, Combustion and Flame, 154, 507-528.

Herbinet, O., W.J. Pitz and C.K. Westbrook (2010). Detailed chemical kinetic mechanism for the oxidation of biodiesel fuels blend surrogate, Combustion and Flame, 157, 893-908.

Kee, R.J., J.A. Miller and T.H. Jefferson (1980). CHEMKIN: A general-purpose, problem-independent, transportable, FORTRAN chemical kinetics code package, Sandia Laboratories.

Lapuerta, M., O. Armas and J. Rodriguez-Fernandez (2008). Effect of biodiesel fuels on diesel engine emissions, Progress in energy and combustion science, 34, 198-223.

Liu, S., J.C. Hewson, J.H. Chen and H. Pitsch (2004). Effect of strain rate on high-pressure nonpremixed nheptane autoignition in counterflow, Combustion and Flame, 137, 320-339

Luo, Z., M. Plomer, T. Lu, S. Som, D.E. Longman, S. Sarathy and W.J. Pitz (2012). A reduced mechanism for biodiesel surrogates for compression ignition engine applications, Fuel, 143-153.

Maroteaux, F. and L. Noel (2006). Development of a reduced n-heptane oxidation mechanism for HCCI combustion modeling, Combustion and Flame, 146, 246-267

Mehl, M., W.J. Pitz, C.K. Westbrook and H.J. Curran (2012). Kinetic modeling of gasoline surrogate components and mixtures under engine conditions, Proceedings of the Combustion Institute, 33(1), 193200

Peters, N. (2000). Turbulent combustion, Cambridge university press.

Pitz, W.J. and C.J. Mueller (2011). Recent progress in the development of diesel surrogate fuels, Progress in Energy and Combustion Science, 37, 330-350.

Searchinger, T., R. Heimlich, R.A. Houghton, F. Dong, A. Elobeid, J. Fabiosa, S. Tokgoz, D. Hayes and T.H. $\mathrm{Yu}$ (2008). Use of US croplands for biofuels increases greenhouse gases through emissions from land-use change, Science, 319, 1238-1240.

Seiser, R., H. Pitsch, K. Seshadri, W. Pitz and H. Gurran (2000). Extinction and autoignition of n-heptane in counterflow configuration, Proceedings of the Combustion Institute, 28, 2029-2037.

Smith, G.P., D.M. Golden, M. Frenklach, N.W. Moriarty, B. Eiteneer, M. Goldenberg, C.T. Bowman, R.K. Hanson, S. Song \& W.C. Gardiner Jr. (1999). GRI-Mech 3.0. URL: 〈http://www.me.berkeley.edu/gri_mech>

Wang, H. and M. Frenklach (1994). Calculations of rate coefficients for the chemically activated reactions of acetylene with vinylic and aromatic radicals, The Journal of Physical Chemistry, 98, 11465-11489.

Westbrook, C.K. (2000). Chemical kinetics of hydrocarbon ignition in practical combustion systems, Proceedings of the Combustion Institute, 28, 1563-1577. 